Egyptian Journal of
Ehysical
Therapy $(E J P T)$
https://ejpt.journals.ekb.eg

\title{
CORRELATION OF DYSPNEA WITH AGE AND SPO2 LEVELS IN COVID-19 AND EFFECTIVENESS OF NEUROPHYSIOLOGICAL FACILITATION IN THE MANAGEMENT OF DYSPNEA-A RANDOMIZED CLINICAL CONTROL TRAIL
}

\author{
Suraj kuma ${ }^{1}$, Gowrishankar Pottur ${ }^{1}$, Sangh Mitra ${ }^{2}$, Ajay Kumar Kushwaha ${ }^{3}$, Pramod Kuma ${ }^{3}$, \\ Shailendra Pal Singh ${ }^{4}$ \\ 1 Department of Physiotherapy, Faculty of Paramedical sciences, Uttar Pradesh University of Medical \\ Sciences, Saifai, Etawah, U.P, India \\ 2 MBBS, DGO. Awantibai Women Hospital, Lucknow, Uttar Pradesh, India \\ 3 Department of Physiotherapy, Uttar Pradesh University of Medical Sciences, Saifai, Etawah, U.P, India \\ 4 Physiotherapist, Department of General Surgery, Uttar Pradesh University of Medical Sciences, Saifai, \\ Etawah, U.P, India
}

\begin{abstract}
*Correspondence to
Gowri Shankar Potturi,

Department of

Physiotherapy, Faculty of

Paramedical Sciences,

Uttar Pradesh University

of Medical Sciences,

Saifai, Etawah, U.P, India

Email:

potturigowrishankar@gm

ail.com
\end{abstract}

Published online:

Sept 2020

\begin{abstract}
:
Purpose: to find the correlation between dyspnea with age, SPO2 levels in COVID-19 and find out the effectiveness of Neurophysiological facilitation of respiration techniques in reliving dyspnea and improving SPO2 levels in COVID-19.

Methods: 117 patients with positive COVID-19 were recruited from COVID19 Hospital in Saifai. They were participated in a single blinded randomized controlled trail. The participants were randomly assigned into experimental group $(n=59)$ and control group $(n=58)$. The experimental group was given physiotherapy in the form of Neurophysiological facilitation of Respiration (NPF), Active cycle of Breathing technique (ACBT) and accupressure. The control group was given physiotherapy in the form of light aerobic exercises, ACBT and accupressure. The levels of dyspnea and $\mathrm{SPO}_{2}$ were assessed pre intervention and after 10 days of treatment.

Results: There was a weak positive correlation between Levels of Dyspnea and age $(r=0.0385) \mathrm{p}>0.05$, which is not statistically significant. There was a strong negative correlation between dyspnea and $\mathrm{SPO}_{2}$ levels $(\mathrm{r}=0.7579) \mathrm{p}<0.05$, which is statistically significant. The experimental group showed better and statistically significant improvement in levels of dyspnea and $\mathrm{SPO}_{2}$ in comparison with control group.

Conclusion:

There is a weak positive correlation between levels of dyspnea with age, strong negative correlation with SPO2 levels in COVID-19 patients. We also conclude that Neurophysiological facilitation improves levels of dyspnea and SPO2 in COVID-19 patients.
\end{abstract}

KEYWORDS: Dyspnea, COVID-19, NPF, Physiotherapy.

\section{Introduction}

Dyspnea commonly defined as difficulty in breathing where a subject experiences breathing discomfort that consists of qualitatively distinct sensations which may vary in intensity ${ }^{1}$. Dyspnea is a highly debilitating symptom, which often leads to anxiety, depression and exercise avoidance. It can worsen deconditioning leading to reduced health-related quality of life. ${ }^{2}$ Onset of dyspnea along with noticeable drop in the oxygen saturation is the key to distinguish COVID-19 from other common illnesses. Researchers observed that though many patients recover from mild symptoms of COVID-19 (nasal congestion, cough, fever, sore throat, diarrhea, abdominal pain, headache, myalgia, back pain, insomnia, fatigue), the onset of dyspnea occurring between day 4 to 10 of onset of symptoms can be discerned from other common illnesses ${ }^{3}$. Extensive inflammation of the bilateral respiratory bronchioles due to excessive activation of proinflammatory cytokines and chemotactic aggregation of t-lymphocytes at the site of 
inflammation may be the possible cause of dyspnea in COVID-194. Early physiotherapeutic interventions in the form of NPF, PNF, ACBT, Accupressure, Aerobic activities improved the respiratory health along with reduction in anxiety and depression may result in good outcome in these cases. Early Physiotherapy when given regularly can avoid the need for mechanical ventilation, thus can prevent mortality in COVID-19 patients. The correlation with age and dyspnea in COVID-19 has not been found yet, and often in published articles mentioned as unknown. The aims of this study are to find the correlation between SPO2 levels with Level of dyspnea, Age with Level of dyspnea in covid subjects and to find the effectiveness of Physiotherapy in relieving dyspnea in COVID-19.

\section{Patients and Methods}

\subsection{Study participants and recruitment criteria:}

All the COVID-19 positive patients with confirmed RT-PCR lab diagnosis, admitted at Uttar Pradesh University of Medical Sciences, COVID-19 Hospital in Saifai, Etawah, Uttar Pradesh, India between June 2020 and September 2020 were eligible for the study. Informed consent was obtained from each patient before recruitment and the Institutional ethical committee of UPUMS, Saifai has given ethical clearance. Two hundred subjects with COVID-19 positive confirmed by RT-PCR are enrolled for the study. Out of 200 subjects 117 subjects have been recruited for the study after satisfying the inclusion criteria. (Fig 1)

\section{Inclusion Criteria:}

1. Confirmed COVID-19 positive with respiratory distress.

2. Patients dependent on Oxygen support.

3. Able to communicate and conscious.

4. Willing to participate.

5. Cooperative and coherent.

\section{Exclusion Criteria:}

1. Intubated patients with respiratory distress.

2. Patients underwent any pulmonary surgical intervention.

3. Unconscious patients.

4. Patients with unstable vital parameters.

\subsection{Study Design:}

The study was a single blinded (Subject blinded) randomized clinical controlled trail. The patients were randomly divided into two groups Group A (Experimental) $n=59$, and Group $B$ (Control) $n=58$ by simple randomization in the pattern of first subject in Group A and second in Group B and so on. At the time of enrollment in the study, the physiotherapist gave the information orally about the study and confirmed with them about participation.

\subsection{Intervention:}

Both the groups received scheduled physiotherapy treatment in addition to the standard care for COVID19 during the hospital stay. The Physiotherapy intervention was delivered once a day (10-15 min) on all days for duration of 10 days. Patients in the both groups were treated by qualified Physiotherapist of the hospital as per the roster issued by the authorities of the hospital as per the COVID-19 guidelines of the hospital. All necessary precautions and guidelines of donning and doffing were followed by the Physiotherapist.

\subsubsection{Experimental Group:}

The physiotherapy intervention consisted of Neurophysiological facilitation of respiration (NPF), Active cycle of Breathing (ACBT), and LU10 (Accupressure point) manual stimulation.

Techniques:

1-Neurophysiological facilitation of respiration: NPF techniques produce reflex respiratory movement response by application of external proprioceptive and tactile stimuli that can alter the rate and depth of breathing. ${ }^{5}$ There are various techniques of NPF, in this case we have performed Thoracic vertebral pressure, co-contraction of the abdomen, intercostal muscle stretch techniques.

a-Thoracic vertebral pressure: The patient was positioned prone. A high manual pressure was applied to the thoracic vertebra in the region of T2-T5 and low manual pressure was applied to the region of T9-T12. The pressure at each vertebra level was given for 20 sec. This increased the rate and depth of breathing by dorsal root mediated intersegmental reflex.

b-Intercostal stretch: The patient was made to lie flat in supine position. The limbs were positioned in neutral position. The therapist with his index and middle finger applied pressure over the intercostal muscles between the 2nd and 3rd rib bilaterally for 20 seconds. The pressure is directed caudally towards the next rib but not towards the vertebra and released. The cycle was repeated for 3 minutes. This stimulates the respiration by intercostal stretch reflex ${ }^{6}$.

c-Co-contraction of abdomen: The patient was made to lie in supine position flat with limbs in neutral position. The therapist then applied moderate and firm pressure on the lower ribs and pelvis at right angles to 


\section{Figure 1: CONSORT Flow Diagram}

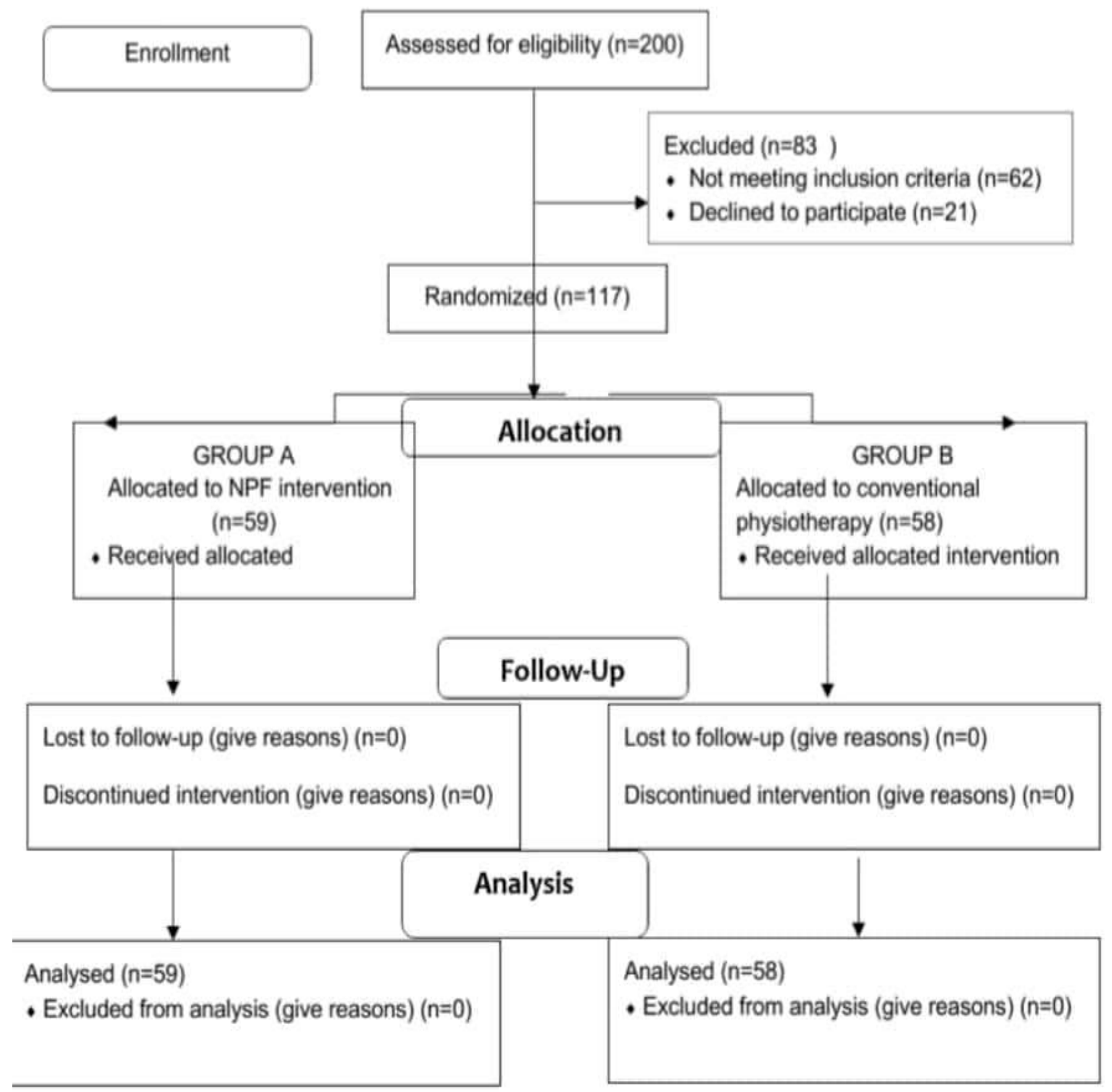

Please cite this article as follows Suraj k, Gowrishankar P, Sangh M, Ajay K, Pramod K, Shailendra P. Correlation of dyspnea with age and spo2 levels in covid-19 and effectiveness of neurophysiological facilitation in the management of dyspnea. EJPT. Sept 2020; 4:25-

31. 
the patient on the same side. The technique was repeated bilaterally one after the other side. The pressure was applied for 20 seconds. The cycle was repeated for 3 minutes alternatively. This technique activates the abdominal muscles by stretch reflex.

2-Active cycle of Breathing Technique (ACBT): The technique was performed in three steps ${ }^{7}$

a-Breathing control: This helps in relieving the tightness and difficulty in breathing and promotes relaxation. The patient was asked to breathe in and out gently through the nose while keeping the shoulders relaxed and he was asked to close the eyes and concentrate on breathing.

b-Deep breathing exercises: The patient was asked to take long, slow and deep breath through nose, holds for 2-3 seconds and breathes out gently and relaxed like a sigh.

c-Forced expiratory technique: The patient was asked to take a long breath in and to blow out in a single phase through mouth.

3-Accupressure: Accupressure is a method of massaging various acupuncture points with fingertip or knuckles ${ }^{10}$. Accupressure has proved beneficial in patients with respiratory disease, associated with cough, dyspnea and congestion ${ }^{11,12,13}$.

Technique: We have chosen the LU1 of the lung meridian which is situated at the index finger. The point was stimulated with the therapist thumb for 20 seconds, 5 cycles in each session. This point is believed to increase oxygenation, decrease cough and respiratory distress.

2.3.2. Control Group: Patients in the controlled group are taught and made to perform light aerobic exercises, deep breathing exercises once or twice daily for 15 repetitions.. The group was given pictorial literature and instructions in local language (Hindi) for better understanding. The physiotherapist has taken all the care for adherence of the patient with exercise protocol by regular communication and counseling.

The following exercises were recommended for 15 repetitions in 2 sets:

a) Ankle pumping exercises in long sitting.

b) Knee to chest exercise in long sitting.

c) Wrist and finger exercises in folded leg sitting.

d) Shoulder ROM exercises in sitting.

e) Lateral trunk bending exercises in folded leg position.

f) Neck ROM exercises.

g) Diaphragmatic breathing exercises

h) ACBT.

i) LU10 accupressure.

\subsection{OUTCOME MEASURES}

The primary outcomes were level of dyspnea and
SPO2 levels. The outcomes are measured pre intervention and 10 days after the intervention by the same physiotherapist who is delivering the physiotherapy. The grading of dyspnea is tabulated in table 1.(Table 1).

\section{Table 1: Grading of Dyspnea}

\begin{tabular}{ll}
\hline GRADE & \multicolumn{1}{c}{ DESCRIPTION } \\
\hline $\mathbf{1}$ & $\begin{array}{l}\text { Difficulty in breathing on } \\
\text { unaccustomed activities }\end{array}$ \\
$\mathbf{2}$ & $\begin{array}{l}\text { Difficulty in breathing on } \\
\text { accustomed activities }\end{array}$ \\
$\mathbf{3}$ & $\begin{array}{l}\text { Difficulty in breathing on Activities } \\
\text { of daily living (ADL) }\end{array}$ \\
$\mathbf{4}$ & $\begin{array}{l}\text { Difficulty in breathing at rest } \\
\text { Difficulty in breathing while lying } \\
\text { flat (Orthopnea) }\end{array}$ \\
\hline
\end{tabular}

\subsection{Statistical analysis:}

To find out the correlation between dyspnea with age and SPO2 levels, Pearson correlation coefficient (r) was calculated. For patient's characteristics, continuous data are summarized as mean $+/$ - standard deviation. Within the group differences (Pre and post intervention) were tested by student paired ' $t$ ' test. Between - groups differences were tested with student unpaired ' $t$ ' test. For all analyses, a 2 -sided $\mathrm{p}<0.05$ was considered statistically significant. All the analyses were performed using Graph Pad statistical calculator.

\section{Table 2: Demographic and baseline characteristics of patients}

\begin{tabular}{lll}
\hline Group & A & B \\
\hline
\end{tabular}

No. of subjects

$59 \quad 58$

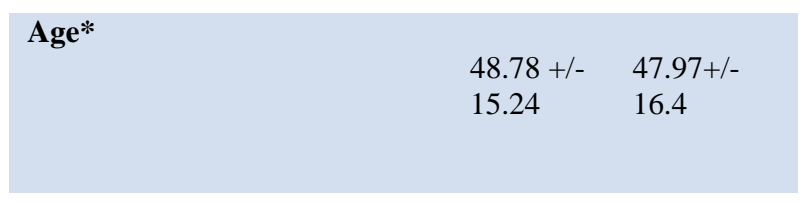

Male: Female ratio

$51: 8$

49:11

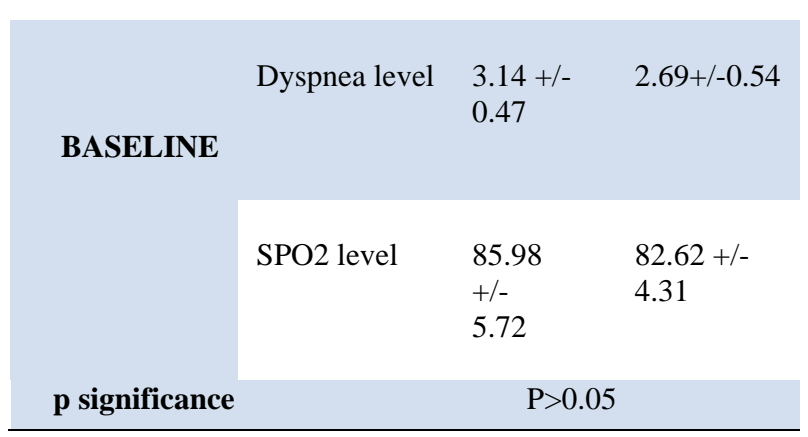


* Mean+/-SD. A=Experimental group. $B=$ Control Group

Table 3: Comparison of Dyspnea and Spo2 Levels in Group A And Group B Pre-intervention And Post Intervention

\begin{tabular}{|c|c|c|c|c|c|c|c|}
\hline $\begin{array}{l}\text { Dys } \\
\text { pnea }\end{array}$ & $\begin{array}{l}\text { Pre } \\
\text { test }\end{array}$ & $\begin{array}{l}\text { Pos } \\
\text { t } \\
\text { Tes } \\
\text { t }\end{array}$ & $\begin{array}{l}\mathbf{t} \\
\text { Va } \\
\text { lue }\end{array}$ & $\begin{array}{l}\text { p } \\
\text { Val } \\
\text { ue }\end{array}$ & $\begin{array}{l}\text { Pretes } \\
\text { t-Post } \\
\text { Test } \\
\text { Differ } \\
\text { ences }\end{array}$ & $\begin{array}{l}\text { t } \\
\text { val } \\
\text { ue }\end{array}$ & $\begin{array}{l}\text { p } \\
\text { Val } \\
\text { ue }\end{array}$ \\
\hline $\begin{array}{l}\text { GR } \\
\text { OUP } \\
\text { A }\end{array}$ & $\begin{array}{l}3.1 \\
4+/- \\
0.4 \\
7\end{array}$ & $\begin{array}{l}1.0 \\
2+/- \\
0.5 \\
1\end{array}$ & $\begin{array}{l}23 . \\
35\end{array}$ & $\begin{array}{l}\mathrm{p}<0 \\
.05\end{array}$ & $\begin{array}{l}2.12+/ \\
-0.7\end{array}$ & $\begin{array}{l}12 . \\
18\end{array}$ & $\begin{array}{l}\mathrm{p}<0 \\
.05\end{array}$ \\
\hline $\begin{array}{l}\text { GR } \\
\text { OUP } \\
\text { B }\end{array}$ & $\begin{array}{l}2.6 \\
9+/- \\
0.5 \\
4\end{array}$ & $\begin{array}{l}2.1 \\
2+/- \\
0.7 \\
7\end{array}$ & $\begin{array}{l}6.3 \\
8\end{array}$ & $\begin{array}{l}\mathrm{p}<0 \\
.05\end{array}$ & $\begin{array}{l}0.57+/ \\
-0.68\end{array}$ & & \\
\hline $\begin{array}{l}\text { SPO } \\
2 \\
\text { level }\end{array}$ & $\begin{array}{l}\text { Pre } \\
\text { test }\end{array}$ & $\begin{array}{l}\text { Pos } \\
\text { t } \\
\text { Tes } \\
\text { t }\end{array}$ & $\begin{array}{l}\mathbf{t} \\
\text { Va } \\
\text { lue }\end{array}$ & $\begin{array}{l}\text { p } \\
\text { Val } \\
\text { ue }\end{array}$ & $\begin{array}{l}\text { Pretes } \\
\text { t-Post } \\
\text { Test } \\
\text { Differ } \\
\text { ences }\end{array}$ & $\begin{array}{l}\text { t } \\
\text { val } \\
\text { ue }\end{array}$ & $\begin{array}{l}p \\
\text { Val } \\
\text { ue }\end{array}$ \\
\hline $\begin{array}{l}\text { GR } \\
\text { OUP } \\
\text { A }\end{array}$ & $\begin{array}{l}85 . \\
98 \\
+/- \\
5.7 \\
2\end{array}$ & $\begin{array}{l}96 . \\
03 \\
+/- \\
1.7 \\
2\end{array}$ & $\begin{array}{l}14 . \\
32\end{array}$ & $\begin{array}{l}\mathrm{p}<0 \\
.05\end{array}$ & $\begin{array}{l}10.07+ \\
/-5.36\end{array}$ & $\begin{array}{l}4.1 \\
5\end{array}$ & $\begin{array}{l}\mathrm{p}<0 \\
.05\end{array}$ \\
\hline $\begin{array}{l}\text { GR } \\
\text { OUP } \\
\text { B }\end{array}$ & $\begin{array}{l}82 . \\
62 \\
+/- \\
4.3 \\
1\end{array}$ & $\begin{array}{l}89 . \\
41 \\
+/- \\
4.2\end{array}$ & $\begin{array}{l}19 . \\
02\end{array}$ & $\begin{array}{l}\mathrm{p}<0 \\
.05\end{array}$ & $\begin{array}{l}6.79+/ \\
-2.72\end{array}$ & & \\
\hline
\end{tabular}

\section{Results}

A total of 117 patients were included in the study. There were no statistically significant baseline differences between groups except that the experimental group had a higher proportion of males (table 2). The correlation between the dyspnea and age was calculated by Pearson correlation coefficient. Level of dyspnea and age were found to be weak positively correlated, $r=0.0385$, $p>0.05$. Level of dyspnea and SPO2 levels were found to be strong negatively correlated, $r=-0.7579, \mathrm{p}<0.05$.
(Fig 3). Both the groups have shown significant improvement in dyspnea and $\mathrm{SPO} 2$ levels and are statistically significant at $p<0.05$ (Fig 3). But Group A, has shown greater improvement in dyspnea and $\mathrm{SPO} 2$ levels than Group B, the differences between the groups are extremely statistically significant, $p<0.05$. (Table 3 ). To quantify the difference between two groups and to emphasize the size of difference, effect size was calculated by Cohen's d for Level of dyspnea and SPO2 levels. The effect size was large.

\section{Discussion}

In this randomized controlled trail, we found that there is weak positive correlation between level of dyspnea and age in COVID-19 patients. It indicates that any age group can suffer from dyspnea and the level of dyspnea cannot be attributed to age in COVID-19. Our findings are contrary to the findings of the study by Best all et.al ${ }^{14}(1999)$ and Sita Sharma et.al ${ }^{15}(2019)$ which showed that there is a strong correlation between age and level of dyspnea in Chronic obstructive pulmonary disease (COPD) patients. Till date there were no researches done to find the correlation between age and level of dyspnea in COVID-19 and is often published asunknown ${ }^{1 .}$ From our study we found that there is a strong negative correlation between level of dyspnea and SPO2 levels, indicating that the SPO2 levels decrease with an increase in grade of dyspnea in COVID-19 cases or vice-versa, which are found to be in support of the study by Tibor Gondos et.al $(2016)^{17}$ in non-covid cases. In a study by Sebastiaan Dhont et.al $(2020)^{18}$, described an interesting concept of 'happy' hypoxemia. The 'Happy' hypoxemia indicates low oxygen saturation levels (SPO2) with no respiratory distress (Dyspnea). Guan et.al (2020) ${ }^{19}$ also reported that only $18.7 \%$ of 1099 hospitalized COVID-19 patients, despite low SPO2 levels and abnormal CT scans had minimal respiratory distress. Both the studies are in contrary with our findings. In our study, we didn't find any happy hypoxemic case.

In our study, we found that the experimental group has shown better and significant results in improving levels of dyspnea and SPO2. Low SPO2 levels are often causing high mortality in COVID-19 cases $^{20}$. It is very important to improve the SPO2 levels to prevent the mortality in COVID-19 cases. NPF techniques increase the depth of breathing, decrease respiratory rate and increase the arousal responses ${ }^{21}$. The technique used in NPF stimulates the proprioceptors in the lower intercostals, spinal muscles facilitating phrenic motor neurons, increasing thoracic and abdominal excursions 
thus increasing the tidal volume and SPO2. In our study, after administration of NPF techniques, the SPO2 levels improved tremendously and dyspnea levels reduced significantly which are' in support of the study by Sharma C et.al (2017) $)^{22}$ on neonates. The stimulation of ventilator muscles by proprioceptive and tactile stimuli by NPF techniques resulted in expansion of ribs, increased epigastric excursion, respiratory depth and rate. It also properly aligns the respiratory muscles and respiratory rhythms. Neurophysiological facilitation of respiration uses external proprioceptive and tactile stimuli that produce reflex respiratory movements. The technique used in Neurophysiological facilitation of respiration improves tidal volume, minute volume and oxygen saturation (SPO2 level). Our study had similar results in support of the studies by Angela chang et.al (2002) and Dr. Jennifer Nitz $(2003)^{22}$.

\section{Figure 2: Correlation between Dyspnea and AGE, SPO2 levels in COVID-19}

\section{Figure 2: Correlation between Dyspnea and AGE, SPO2 levels in COVID-19}

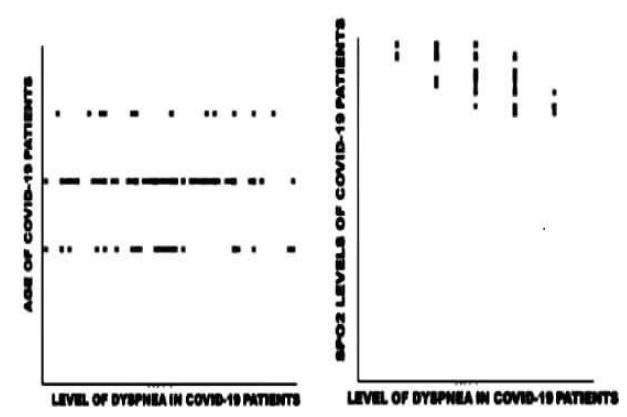

\section{Conclusion}

From this study, we conclude that there is a weak positive correlation between levels of dyspnea with age, strong negative correlation with SPO2 levels in COVID-19 patients. We also conclude that Neurophysiological facilitation improves levels of dyspnea and SPO2 in COVID-19 patients. NPF techniques are recommended to be incorporated in the pulmonary rehabilitation protocols of COVID-19 to avoid mortality due to respiratory distress in COVID19.

\section{LIMITATIONS OF THE STUDY}

1. A simple randomization technique was used.

2. The values calculated are non-invasive. ABG values can be tested for further studies to find the effectiveness of NPF.

\section{Acknowledgments}

The authors acknowledge the authorities of Uttar Pradesh University of Medical Sciences, Saifai, Etawah, Uttar Pradesh for approval and encouragement.

\section{FUNDING}

This research did not receive any specific grant from funding agencies in the public, commercial, or not-forprofit sectors.

\section{DISCLOSURE OF INTEREST}

The authors report no conflict of interest

\section{References}

1. Dyspnea. Mechanisms, assessment, and management: a consensus statement. American Thoracic Society. Am J RespirCrit Care Med. 1999; 159:321-340.

2. O’Donnell DE, Ora J, Webb KA, et al. Mechanisms of activity-related dyspnea in pulmonary diseases. RespirPhysiolNeurobiol. 2009; 167:116-132.

3. Cohen PA, Hall L, Johns JN, Rapoport AB. The early natural history of SARS-CoV-2 infection: clinical observations from an urban, ambulatory COVID-19 clinic [published online April 20, 2020]. Mayo Clin Proc. doi: 10.1016/j.mayocp.2020.04.010.

4. ShukeNie, Shoumeng Han, HuangqingOuyang et.al. Coronavirus Disease 2019-related dyspnea cases difficult to interpret using chest computed tomography. Respiratory medicine.2020; 167.

5. Dr. HardiniPrajapati, "Effect of Neurophysiological Facilitation [NPF] of Respiration on Ventilation of Mechanically Ventilated Patients: An Experimental Study", 
International Journal of Science and Research, Volume 7 Issue 9, September 2018, 629 - 631.

6. Chang A, Paratz J, Rollston J. Ventilatory effects of neurophysiological facilitation and passive movement in patients with neurological injury. The Australian Journal of Physiotherapy. $2002 ; 48(4): 305-310$.

7. Lewis LK, Williams MT, Olds TS. The active cycle of breathing technique: A systematic review and meta-analysis. Respiratory Medicine, 2012;106(2): 155-172.

8. Gallon A. Evaluation of chest percussion in the treatment of patients with copious sputum production. Respiratory medicine. 1991 Jan 1;85(1):45-51.

9. Van der Schans C, Bach J, Rubin BK. Chest physiotherapy: mucus-mobilization techniques. In: Bach JR, editor. Noninvasive mechanical ventilation. 1st ed. Philadelphia: Hanley \&Belfus Inc.; 2002. p. 259-84.

10. G. Stux, "Acupressure," in Acupuncture: Textbook and Atlas, G. StuxB. Pomeranz, Ed., p. 235, Springer, New York, NY, USA, 1987.

11. S. H. Maa, T. S. Tsou, K. Y. Wang, C. H. Wang, H. C. Lin, and Y. H. Huang, "Selfadministered acupressure reduces the symptoms that limit daily activities in bronchiectasis patients: pilot study findings," Journal of Clinical Nursing, vol. 16, no. 4, pp. 794-804, 2007.

12. H. S. Wu, S. C. Wu, J. G. Lin, and L. C. Lin, "Effectiveness of acupressure in improving dyspnoea in chronic obstructive pulmonary disease," Journal of Advanced Nursing, vol. 45, no. 3, pp. 252-259, 2004.

13. S. L. Tsay, J. C. Wang, K. C. Lin, and U. L. Chung, "Effects of acupressure therapy for patients having prolonged mechanical ventilation support," Journal of Advanced Nursing, vol. 52, no. 2, pp. 142-150, 2005.

14. Bestall JC, Paul EA, Garrod R, Garnham R, Jones PW, Wedzicha JA, et al. Usefulness of the medical research council (MRC) dyspnoea scale as a measure of disability in patients with chronic obstructive pulmonary disease. Thorax 1999;54:581-6.

15. Sharma S, Sharma P. Prevalence of dyspnea and its associated factors in patients with chronic obstructive pulmonary disease. Indian J Respir Care 2019;8:36-41.

16. Ora, J., Liguori, C., Puxeddu, E. et al. Dyspnea perception and neurological symptoms in nonsevere COVID-19 patients. NeurolSci (2020).

17. Gondos T, Szabó V, Sárkány Á, Sárkány A, Halász G. Estimation of the severity of breathlessness in the emergency department: a dyspnea score. BMC Emerg Med. 2017;17(1):13. Published 2017 Apr 26. doi:10.1186/s12873-017-0125-6.

18. Dhont, S., Derom, E., Van Braeckel, E. et al. The pathophysiology of 'happy' hypoxemia in COVID-19. Respir Res 21, 198 (2020).

19. Guan W, Ni Z, Hu Y, Liang W, Ou C, He J, et al. Clinical characteristics of coronavirus disease 2019 in China. N Engl J MedMassachusetts Medical Society. 2020. Epub ahead of print.

20. Arentz M, Yim E, Klaff L, et al. Characteristics and outcomes of 21 critically ill patients with COVID-19 in Washington State [published online March 19, 2020]. JAMA.

21. Sharma C, Sharma A, Lal R, Effect of NeuroPhysiological Facilitation Techniques on Vitals of Preterm Neonates. SRHU Medical Journal, 2017;1(2):80-83.

22. Nitz J, Burke B. A study of the facilitation of respiration in myotonic dystrophy. Physiotherapy research international. 2003 Nov;7(4):228-38. 